\title{
Histopathology of Gastrointestinal Tract Malignancies - A Two Year Retrospective Study
}

\author{
Meera Shantaram Mahajan*, Neha Amrut Mahajan, Shrinivas Shankarrao Kale and Chandrashekhar Prabhakar Bhale \\ Department of Pathology, MGM Medical college and hospital, Aurangabad (Maharashtra), India
}

\begin{abstract}
Background: Incidence of gastrointestinal malignancies is gradually increasing. The aim of the study is to determine age, sex and relative frequencies of various malignancies.

Methods: Gastrointestinal malignancies diagnosed between January 2014 to December 2015 in MGM Medical College and Hospital, Aurangabad. In this descriptive retrospective study, total of 180 cases of gastrointestinal malignancies were diagnosed in our institution. Demographic and histopathological data were retrieved from the case files and histopath request forms. The slides were microscopically reviewed to confirm the diagnosis.

Result: The mean age of the patients was 56 years $(\mathrm{SD}=13)$. Peak incidence was in between 40-60years. Male to female ratio of $1.5: 1$ was recorded. The common GI malignancies were esophageal(50.8\%) followed by large intestine (50\%).Other anatomic sites affected are stomach(36.6\%), perianal region(9.1\%) and small intestine(3.3\%).Microscopically, adenocarcinoma was the commonest malignancy(67\%) followed by squamous cell carcinoma( $28 \%)$.

Conclusion: Gastrointestinal tract malignancies are one of most common cancers in our country. . The incidence has been increasing due to life style changes and these cancers are usually diagnosed late when the disease has already invaded the lamina propria and musculature, because in early stages, the patient usually complains of trivial and nonspecific symptoms. Hence a new look to epidemiological studies in gastric cancer is necessary along with necessary focus on lifestyle modification.
\end{abstract}

Keywords: Gastrointestinal Malignancy, Adenocarcinoma, Squamous Cell Carcinoma

\section{Introduction}

The gastrointestinal system has been reported the second common site for the non cutaneous cancer and second reason of the mortality resulted from cancer. ${ }^{[1]}$ The pattern and distribution of gastrointestinal malignancies differ in different geographical areas, carcinoma esophagus being most frequent in Iran, carcinoma stomach in eastern Asian countries and colorectal carcinomas in developed world. ${ }^{[2]}$ The geographic difference depends on the food, environment and genetic predisposition. People having low fiber intake in diet have high incidence of colorectal carcinomas whereas those consuming hot beverages have high incidence of esophagus carcinoma. Young people have less GI neoplasms as the dose and time of exposure of carcinogenic agent is less. ${ }^{[3]}$ This study is aimed at determining age, sex and relative frequencies of various gastrointestinal biopsies in MGM Medical College and hospital, Aurangabad.

\section{Materials and Methods}

This is a descriptive retrospective histopathological study conducted at MGM Medical College and hospital,
Aurangabad. All records are from 180 consecutive patients who were documented pathologically to have gastrointestinal malignancy from Jan 2014 to Dec 2015.Demographic and histopathological data were retrieved from the case files and histopath request forms. Slides and paraffin embedded blocks of pathological specimens of gastrointestinal tissues were retrieved from archives and new sections were cut and processed with haematoxylin and eosin stain. The slides were microscopically reviewed to confirm the diagnosis.

\section{Result}

Our study included various gastrointestinal malignancy received in our department. Total malignancy cases were 180 during the year 2014(82 cases) to 2015(98 cases). Out of 180 cases, 108 were males and 72 were females. The male to female ratio was 1.5:1. The distribution of GI malignancy cases in both the sexes is shown in Figure1.

Age average of the patients with GI cancer was 56 years $(\mathrm{SD}=13)$ and minimum and maximum age of the patients were 17 years and 92 years respectively. The incidence of different GI malignancies based on different age 
groups is depicted in Table1.Maximum number of cases were in 40 to 60 age groups.

Majority of GI malignancies were found in esophagus $(50.8 \%)$ followed by large intestine $(50 \%)$. Other anatomic sites affected are stomach(36.6\%),small intestine(3.3\%) and perianal region( $9.1 \%$ ) shown in Table 2.

Histologically adenocarcinoma was main type comprising $67 \%$ followed by squamous cell carcinoma which makes up $28 \%$ of all malignancies.Other histological variants found in our study were round cell tumor $2 \%$,GIST $2 \%$ and adenosquamous carcinoma $1 \%$ as shown in figure 2 and 3.

\section{Discussion}

All over the world, GI tract malignancies form a significant proportion of malignant tumors in both sexes. ${ }^{[2]}$ It is not uncommon and its incidence varies from region to region. Our study reveal the total number of GI malignancy received from 2014 and 2015 were 180.In our study, majority malignancy was detected after age of 30 year and maximum number were seen between 41 to 60 years. In various studies major GI malignancy is seen after age of 60 year. ${ }^{[2,4]}$. Early presentation of malignancy is observed due to several reasons including change in dietary habits due to urbanization, upsurge of confectionary food outlet rich in refined carbohydrate low fiber content and fresh fruit, lead to increase in increased transit time so GI malignancies are not rare as previous studies..$^{[5,6]}$

Out of 180 cases, commonest malignancy is adenocarcinoma $120(67 \%)$ case followed by squamous cell carcinoma 50( $27.7 \%$ ) cases. Most of the squamous cell carcinoma were presented from esophagus whereas adenocarcinoma from colon, that correlate well with other study. ${ }^{[5,6,7]}$ Esophageal cancer is the $15^{\text {th }}$ common cancer in developed countries and $4^{\text {th }}$ in developing world. ${ }^{[8]}$ Squamous cell carcinoma is more common worldwide, but adenocarcinoma is on the rise in the United states and other western countries. In our study most common malignancy is esophageal

Table 1: Agewise distribution of GI malignancies.

\begin{tabular}{|l|c|c|c|c|c|}
\hline Age & Adenoca & Round cell ca & SCC & GIST & Adenosquamous ca \\
\hline $1-15$ & 00 & 00 & 00 & 00 & 00 \\
\hline $16-30$ & 01 & 00 & 02 & 00 & 00 \\
\hline $31-45$ & 08 & 02 & 10 & 01 & 03 \\
\hline $46-60$ & 80 & 02 & 03 & 00 & 00 \\
\hline $61-75$ & 20 & 00 & 10 & 00 & 00 \\
\hline$>75$ & 11 & 00 & $\mathbf{5 0}$ & $\mathbf{0 4}$ & $\mathbf{0 2}$ \\
\hline Total & $\mathbf{1 2 0}$ & $\mathbf{0 4}$ & & & 00 \\
\hline
\end{tabular}

Table 2: Distribution of different histological subtypes in different locations.

\begin{tabular}{|c|c|c|c|c|c|}
\hline \multicolumn{6}{|c|}{ Histological subtypes as per location } \\
\hline \multicolumn{6}{|l|}{$\begin{array}{l}70 \\
60\end{array}$} \\
\hline \multicolumn{6}{|l|}{50} \\
\hline \multicolumn{6}{|l|}{40} \\
\hline 30 & & & & & \\
\hline \multicolumn{6}{|l|}{20} \\
\hline \multirow{3}{*}{$\begin{array}{r}10 \\
0\end{array}$} & & & $n$ & \\
\hline & & & Round cell & & Adenosqua \\
\hline & Adenoca & $\mathrm{SCC}$ & $\begin{array}{l}\text { Kound cell } \\
\text { tumor }\end{array}$ & GIST & mous ca \\
\hline Esophagus & 10 & 45 & 4 & 0 & 2 \\
\hline 口Stomach & 40 & 0 & 0 & 4 & 0 \\
\hline Small intestine & 4 & 0 & 0 & 0 & 0 \\
\hline Large intestine & 60 & 0 & 0 & 0 & 0 \\
\hline Perianal region & 6 & 5 & 0 & 0 & 0 \\
\hline
\end{tabular}




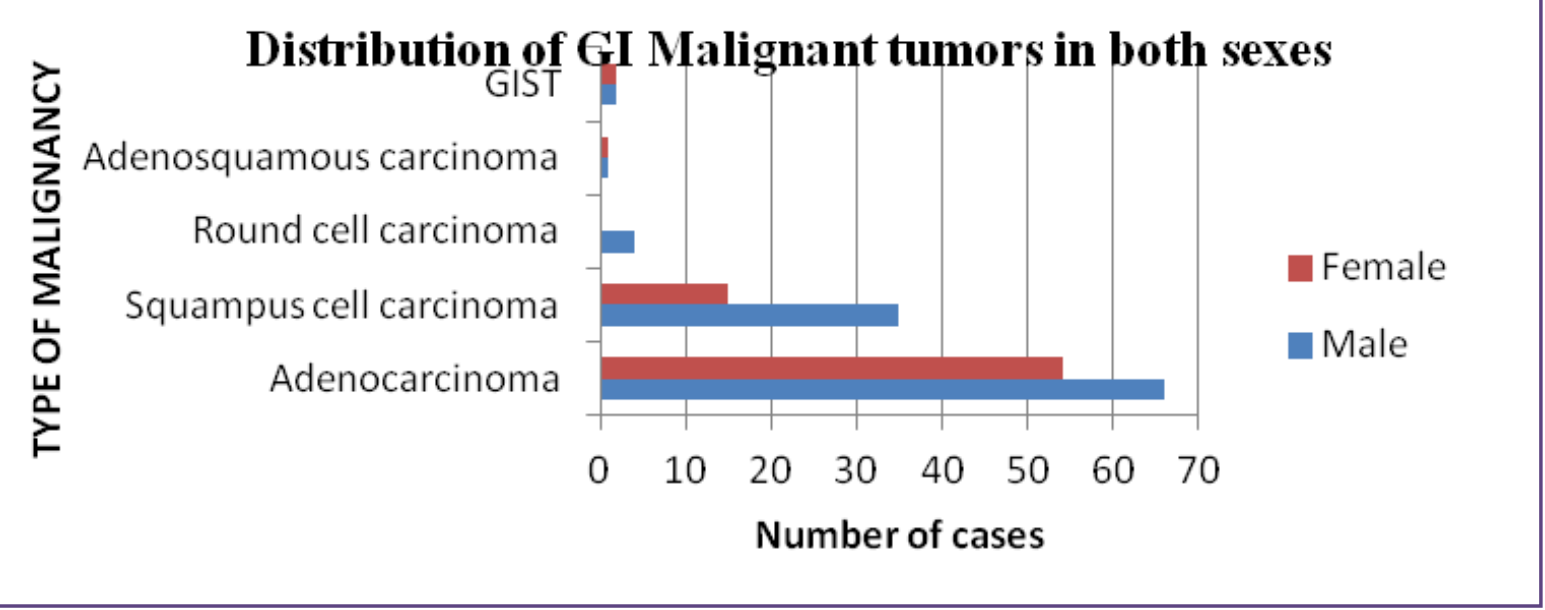

Fig. 1: Distribution of GI malignancy cases in both the sexes.

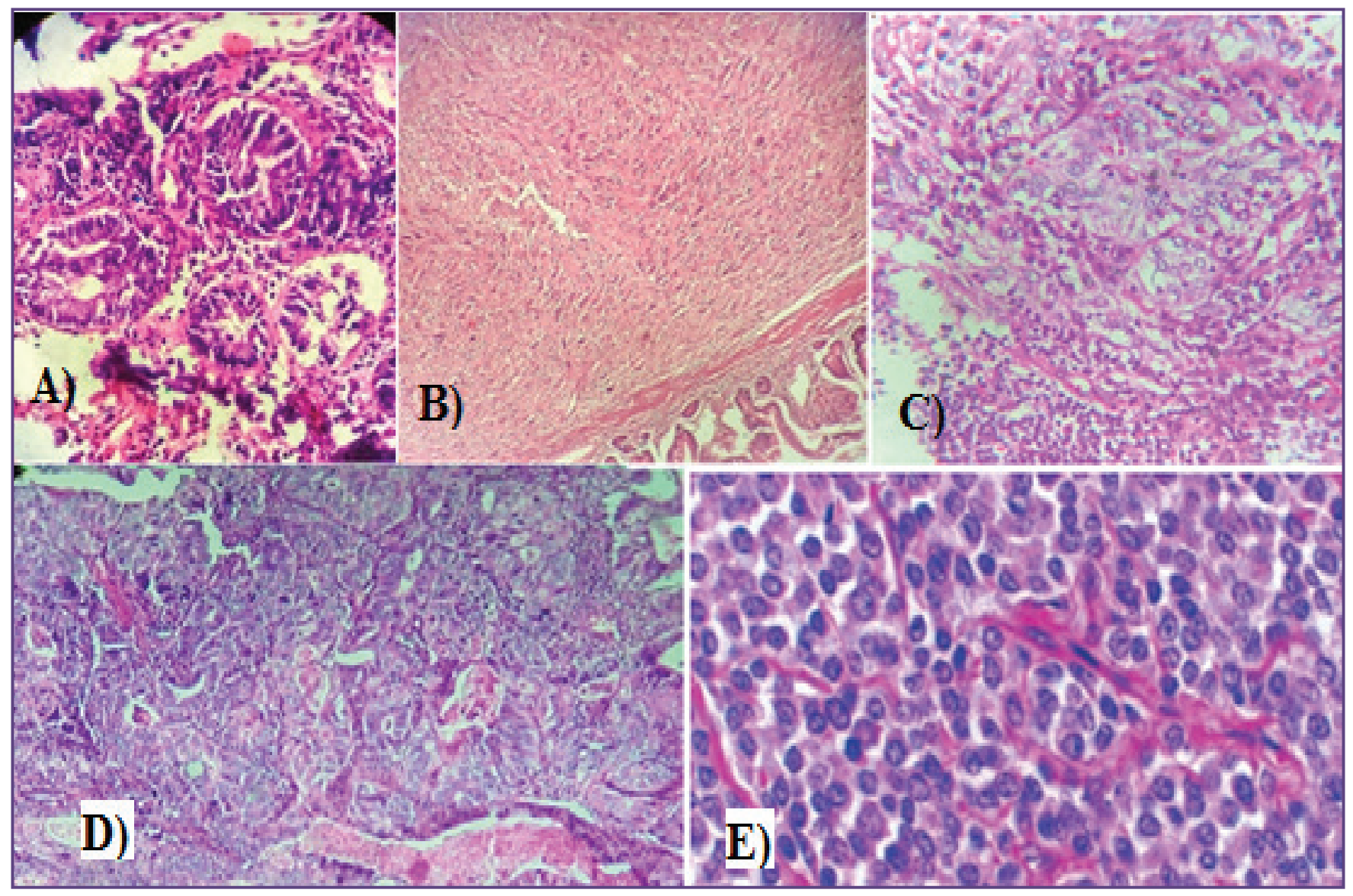

Fig . 2: Figure showing H \& E of tumor A)Adenocarcinoma, B)Gastrointestinal stromal tumor(GIST), C)Squamous cell carcinoma, D)Adenosquamous carcinoma, E)Round cell tumor. 


\section{Distribution of malignancies}

Adenocarcinoma $\square$ SCC $\square$ Adenosquamous ca $\square$ GIST $\square$ Round cell tumor

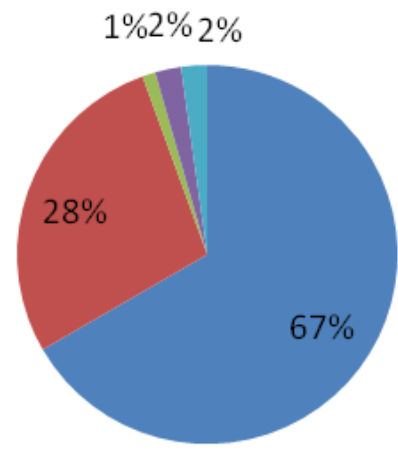

Fig. 3:Histological distribution of malignancies.

cancer $(50.8 \%)$. Our findings correlate with study of Jijo $\mathrm{V}$ Cherian et al in Tamil Nadu( South India).Higher rate of squamous cell carcinoma in indian subcontinent may be due to tobacoo chewing, smoking, alcohol intake, ingestion of hot and spicy food. ${ }^{[9]}$

About $60 \%$ of stomach cancer occurs in the developing countries. The areas of highest incidence are eastern Asia, Eastern Europe and some parts of South Africa, whereas in northern America and Europe the incidence is low. In our study 44 cases of stomach malignancy were seen, out of which 40 were adenocarcinoma and 4 were of Gastrointestinal stromal tumors (GIST).GIST is a heterogenous group of tumors frequently located in stomach. In our study all the cases of GIST were located in stomach. This finding correlates with studies that found that stomach is the commonest location for gastrointestinal tumors. ${ }^{[10,11]}$

Though small intestine represent maximum surface area in gastrointestinal tract small bowel neoplasm is rare compared to esophagus and colorectal carcinoma and account for only $1-2 \%$ of all gastrointestinal neoplasms. ${ }^{[12]}$ The incidence of colon and rectal cancer is higher in developed country than in developing countries. ${ }^{[13]}$ In developed countries, it is among the third most common cancer and colorectal carcinoma is commonest gastrointestinal neoplasm. This geographic difference represent the effect of different dietary habbit. In a study by Fatima et al in south Nigeria shown colorectal carcinoma was the most common malignant gastrointestinal neoplasm accounting for 59 percent. Rate of colorectal carcinoma is comparable to other studies in India except that mean age is decreasing to 45 years. ${ }^{[14]}$ Screening studies should be considered to determine possible risk factor by introducing digital rectal examination and occult blood test at an early age.

\section{Conclusion}

Gastrointestinal tract malignancies are one of most common cancers in our country. The incidence has been increasing due to life style changes and many variables as smoking, alcoholism, tobacco, altered diet habits etc. The diagnosis of these cancers are usually late when the disease has already invaded the lamina propria and musculature, because in early stages, the patient usually complains of trivial and nonspecific symptoms. Hence a new look to epidemiological studies in gastric cancer is necessary. And also it is mandatory to focus on lifestyle modification such as reduced salt intake and increased vegetable and fruits consumption, together with avoidance of smoking and alcoholism.

\section{Reference}

1. Yasemi M, Ahmadi MRH, Peyman H, Yasemi MR, Khajavikhan J, Hemati K. A 7 years retrospective study of gastrointestinal cancers incidence in the western Iran. Journal of clinical and diagnostic research. 2015;9(7):EC01EC05.

2. Jamal S, Mamoon N, Mushtaq S, Luqman M. Analysis of Gastrointestinal malignancies at Armed forces institute of Pathology, Ravalpindi, Pakistan. Asia Pacific Journal of Cancer prevention, 2005;6: 497-500.

3. Patel MM, Gamit B, Patel PR. Analysis of Gastrointestinal Malignancy: A five years study. National Journal of Community Medicine. 2012;3;555-557.

4. Pauna C, Lazar E. Colorectal Carcinoma - Epidemiological and Histopathological aspect. Cercetari Experimentale and Medico-Chirurgicale. 2006; anuIXIII:53-56.

5. Khurshed A, Ahmed R, Yasmin Bhurgri.Primary Gastrointestinal malignancies in childhood and Adolescence - an Asian Perspective. Asian Pacific Journal of Cancer prevention. 2007;8:613-617. 
6. Abdulkareem FB, Abudu EK, Awolola NA, et al. Carcinoma in Lagos and sagamu, Southwest Nigeria: A histopathological review. World Journal of Gastroenterology 2008;14(42):6531-6535.

7. Chandra N, Khan AR, Romana M, Lateef S. Histopathology of Gastric cancer in Kashmir - A five year retrospective Analysis. JK SCIENCE. 2007;9(1):21-23.

8. Jijo V.Cherian, Ramalingam Sivaraman, Arun K. Muthusamy, Venkataraman Jayanthi. Carcinoma of the Esophagus in Tamil Nadu(South India):16 years trend from Tertiary Center. J Gastrointestin Liver Dis September 2007;16(3):245-249.

9. Kollarova H, Machova L, Horakova D, Janoutova G, Janout V.Epidemiology of Esophageal Cancer - An overview Article. Biomed Pap Med Fac Univ Palacky Olomouc Czech Rpub.200;151(1):17-28

10. Mieittinen M, Sobin LH, Lasota J. Gastrointestinal stromal tumors of stomach:A clinicopathologic, immunohistochemical and molecular genetic study of 1765 cases with long term follow up. Am J Surg Pathol (2005) 29:52-68

11. Berman J, O'Leary TJ. Gastrointestinal stromal tumor workshop. Hum Pathol 2001;32:578-582.

12. Hatzaras I, Palesty JA, Abir F, et al. Small Bowel Tumors Epidemiologic and Clinical Characteristics of 1060 Cases from the Connecticut Tumor Registry.(Reprinted)ARCH SURG. 2007;14:229-235.

13. Parkin DM, Pisani P, Ferlay J .Global Cancer Statistics. Cancer Journal for Clinicians. 1999; 49(1):33-63.

14. Laishram RS, Kaiho N, Shimray R, et al. Histopathological Evaluation of Colorectal Carcinoma Status in Manipur, India. International Journal of Pathology; 2010;8(1):5-8.

15. Pishbijari HF, Rad MA, Ghofrani H, Shafaghi A, Toosi $\mathrm{MN}$, Dolatshahi S. A retrospective study of Gastrointestinal Cancers in Theran, Medical Journal of the Islamic Republic of Iran, 2006, 20;.107-110

*Corresponding author:

Dr Neha Amrut Mahajan, 41, Atharva, besides water tank. Vedant Nagar. Railway station road. Aurangabad(431005).Maharashtra. INDIA

Phone: +91 9405107982,

Email: nehaamahajan@yahoo.com

Date of Submission : 02.01.2017

Date of Acceptance : 14.05.2017

Financial or other Competing Interests: None.

Date of Publication : 31.08.2017 